\title{
A incorporação do teste diagnóstico baseado na amplificação de ácidos nucleicos (NAT) para triagem de sangue no SUS: arranjos tecnológicos para a nacionalização do "NAT brasileiro"
}

\author{
| ${ }^{1}$ Koichi Kameda, ${ }^{2}$ Marilena C. D. V. Corrêa, ${ }^{3}$ Maurice Cassier |
}

Resumo: Os testes de ácidos nucleicos (NAT) são ferramentas complementares aos testes sorológicos para controle da transmissão de doenças infecciosas por meio de produtos obtidos a partir do sangue. Em 2002, um decreto do Ministério da Saúde tornou obrigatória a realização do NAT por todos os bancos de sangue, medida dificultada por razóes como os custos necessários para a sua implantação. Como estratégia para a sua incorporação nos bancos de sangue ligados ao SUS, um consórcio público foi criado para desenvolver uma versão local do kit. A partir de métodos de pesquisa qualitativa, os autores analisam essa iniciativa, visando esmiuçar os detalhes da "nacionalização tecnológica" de um teste diagnóstico in vitro. $\mathrm{O}$ artigo descreve como o consórcio compreende o kit e como cada uma das tecnologias que o compóem são obtidas e reunidas no teste brasileiro. A relevância dessa análise é identificar quais os desafios e os limites à produção de testes in vitro para doenças infecciosas no Brasil, assim como a repercussão desse tipo de iniciativa para o sistema nacional de inovação em saúde.

> Palavras-chave: segurança do sangue; teste diagnóstico; testes de ácidos nucleicos (NAT); HIVIAids, hepatites virais, Sistema Único de Saúde.

\author{
1 École des Hautes Études en \\ Sciences Sociales (EHESS). Paris, \\ France (kokameda@gmail.com). \\ ORCID: 0000-0003-1337-6501 \\ ${ }^{2}$ Instituto de Medicina Social, \\ Universidade do Estado do Rio de \\ Janeiro. Rio de Janeiro-RJ, Brasil \\ (correamarilena@gmail.com). \\ ORCID: 0000-0003-3908-8073 \\ ${ }^{3}$ École des Hautes Études en \\ Sciences Sociales (EHESS). Paris, \\ France (cassier@vjf.cnrs.fr). \\ ORCID: 0000-0003-3908-8073
}

Recebido em: 28/07/2018 Revisado em: 10/11/2017 Aprovado em: 21/02/2018 


\section{Introdução}

Testes de ácidos nucleicos (NAT) passaram a ser utilizados para triagem de bolsas de sangue de modo complementar aos testes serológicos, aqueles baseados na busca de anticorpos, a partir do final dos anos 1990. Motivados por relatos de transmissão de doenças infecciosas, em particular, hepatite $\mathrm{C}$, por meio de produtos derivados do sangue, e pela memória recente dos casos de contaminação de pacientes por HIV via transfusão sanguínea e uso de produtos do sangue nos anos 1980, alguns países de alta renda rapidamente adotaram esse teste com o fim de reforçar a segurança do sangue. A incorporação dessa tecnologia por tais países não ocorreu, contudo, sem amplas consideraçóes sobre custo-efetividade, um debate que continua na medida em que países em desenvolvimento cogitam a adoção do NAT (BUSCH; DODD, 2000; CHANDRASHEKAR, 2014; HOURFAR et al., 2008).

Em 2002, um decreto do Ministério da Saúde passou a obrigar todos os bancos de sangue brasileiros a adotarem o NAT. Contudo, a implantação imediata do teste nos bancos de sangue ligados ao SUS, que representam a maior proporção do sangue utilizado no país, teria sido impedida pela falta de registro, à época, de kits comerciais, e, sobretudo, em razão dos preços elevados dos produtos disponíveis no mercado internacional (PETRY, 2013). Com a mudança do governo no ano seguinte, a estratégia utilizada para adoção da tecnologia passou a se inserir num contexto de retomada de uma política industrial e de produção local de produtos usados pelo SUS. Um consórcio tecnológico foi assim constituído para desenvolver uma versão local desse teste, projeto denominado "NAT brasileiro".

Neste artigo, oferecemos uma análise do desenvolvimento do NAT brasileiro, a qual se interessa, por um lado, pelo estudo da articulação entre políticas industriais, de ciência e tecnologia e políticas de saúde pública. Por outro lado, visa esmiuçar os detalhes do desenvolvimento e fabricação do teste, processo chamado de "nacionalizaçáa”" pelos membros do projeto. Descrevemos, assim, como o consórcio compreende o kit - um conjunto de diferentes componentes -, e como cada uma dessas tecnologias são obtidas e reunidas, no NAT brasileiro. A relevância dessa análise é identificar quais os desafios e os limites à produção de testes in vitro para doenças infecciosas no Brasil, assim como a repercussão desse tipo de iniciativa para o sistema nacional de inovação em saúde. Identificamos na literatura poucos 
trabalhos que analisaram mais profundamente essa iniciativa (KRIEGER et al., 2013; PETRY, 2013), o que torna ainda mais relevante este artigo.

Para a condução do estudo, foram utilizados métodos e técnicas de pesquisa dos estudos sociais da inovação e da prática científica. A pesquisa de campo aqui utilizada foi realizada entre 2014 e 2016, e incluiu: entrevistas com pesquisadores e técnicos envolvidos no consórcio NAT (Bio-Manguinhos, Instituto de Biologia Molecular do Paraná e a Universidade Federal do Rio de Janeiro), representantes da Coordenação de Sangue do MS e do setor de produtos para saúde da Anvisa; com pesquisadores e técnicos de dois bancos de sangue (do Hemorio e da Fundação Pró-Sangue, em São Paulo); e com representantes de empresas multinacionais que comercializam testes NAT e reativos para testes moleculares in vitro. A abordagem metodológica citada compreende, também, o seguimento dos diferentes atores e as suas açóes implicados na prática científica (LATOUR, 2011) e a análise dos processos (políticos, técnicos e sociais) que conduzem à inovação, neste caso, em testes para diagnóstico in vitro num país do Sul (ENGEL, 2012).

\section{Relevância e justificativa do estudo}

\section{Testes para triagem de sangue e economia da segurança do sangue}

O sangue total e os produtos dele derivados são vitais em procedimentos médicos, sendo, por isso, considerados tecnologias essenciais (WHO, 2015). Ainda assim, o acesso a produtos seguros a partir do sangue não é uma questão equacionada na maior parte dos países em desenvolvimento. Igualmente problemático é o acesso aos testes para triagem de agentes infecciosos, como HIV, hepatites virais, sífilis, e doenças emergentes, como zika, em bolsas de sangue (WHO, 2011). ${ }^{1}$ Além da triagem clínica, tecnologias para triagem laboratorial e inativação daqueles agentes são ferramentas importantes para o aumento da sua segurança do sangue, como ficou evidente após a notificação de casos de transmissão de doenças, como hepatites virais, HIV/Aids e Chagas, nos anos 1980, por produtos de sangue contaminados (SANTOS et al., 1991).

Em acréscimo à testagem de grupo sanguíneo $\mathrm{ABO}$ e determinação do fator Rh, testes sorológicos e testes de ácidos nucleicos são realizados na rotina dos serviços de hemoterapia em diversos países para triagem de doenças transmissíveis. Os testes sorológicos podem identificar anticorpos ou antígenos para HIV, hepatites B e 
C, sífilis e outras doenças, de acordo com a relevância epidemiológica para o país (HTLV1-2, doença de Chagas e malária, por exemplo).

Os testes de ácidos nucleicos (NAT) são baseados em técnicas de amplificação de ácidos nucleicos que permitem a identificação muito mais rápida do agente infeccioso, antes da formação da resposta imunológica. O grande objetivo é reduzir a janela imunológica, definida como o tempo exigido para a formação de anticorpos pelo corpo humano, que são, por sua vez, os alvos dos testes sorológicos.

O teste NAT foi inicialmente utilizado pela indústria europeia de fracionamento de plasma para a triagem de material a ser empregado na produção de hemoderivados, sendo a transmissão de doenças infecciosas por meio do uso de produtos contaminados o motivador principal da aplicação dessa tecnologia. São relatados, por exemplo, os episódios de transmissão de hepatite $\mathrm{C}$ em pacientes de dez países em razão da utilizaçáo do hemoderivado Gammagard, uma preparação de imunoglobulina intravenosa (derivada do plasma). Esse evento indesejado levou à retirada do produto do mercado mundial pela empresa produtora Baxter Healthcare Corporation (FLANAGAN; SNAPE, 1998; GOMPERTS, 1996).

O primeiro serviço de hemoterapia a implementar o NAT situava-se na Alemanha e suas atividades tiveram início em 1997. Com a confirmação da viabilidade da implementação do NAT na rotina da triagem de sangue, em 1998 e 1999, bem como sua posterior industrialização por empresas multinacionais, o teste foi rapidamente disseminado, em particular nos países de alta renda. Em 2010, reportou-se que 33 países já tinham adotado ou estavam em vias de adotar o teste NAT para HCV e HIV-1, e 27 países tinham adotado ou estavam em vias de utilizar o teste NAT para HBV (ROTH et al., 2012).

Essa disseminação, no entanto, foi precedida por uma discussão sobre custoefetividade, principalmente em razão dos custos para sua incorporação (ROTH et al., 2012). Alguns países em desenvolvimento, como a África do Sul (2000), Tailândia (2006) e Malásia (2007), também adotaram o teste. A OMS (WHO, 2009), por sua vez, é hesitante em recomendar a sua adoção por todos os países, orientando-os, antes, a pesarem benefícios e custos relacionados ao preço dos testes e da infraestrutura necessária e a realizarem-no apenas quando já possuam a triagem sorológica bemestabelecida, e se houver um benefício adicional claro e evidente (WHO, 2009).

A testagem de sangue com NAT, contudo, se revelou benéfica em países onde a soroprevalência (frequência de indivíduos com resultado positivo para 
anticorpos contra um determinado agente infeccioso) da transmissão de doenças infecciosas por meio de transfusão sanguínea é alta, como é o caso da maioria dos países em desenvolvimento. Por outro lado, a sua incorporação por esses países segue dependendo principalmente da disponibilidade de recursos, uma vez que é necessária a mobilização de infraestrutura, equipamentos, consumíveis, expertise técnica e o fornecimento de kits, cujos produtos disponíveis no mercado possuem preços elevados (HANS; MARWAHA, 2014).

Nesse contexto, os produtos de sangue passam a ser vistos não apenas como bens essenciais à saúde e à manutenção da vida, mas ta mbém como fonte de conta minação. O biovalor do sangue se relaciona à capacidade de os países gerenciarem a qualidade desse bem essencial (BUSBY et al., 2014). Um dos desafios da segurança do sangue está, portanto, diretamente relacionado aos custos dos requisitos de segurança e ao progresso tecnológico na triagem do sangue. O desafio é ainda maior para os países com recursos limitados (JERSILD; HAFNER, 2008).

Este trabalho sobre o sangue humano, seu uso na prática médica e sua apropriação pela indústria de biotecnologia traz uma reflexão sobre a economia do sangue a partir da análise do acesso aos testes de triagem que aumentam a segurança do produto; em outras palavras, uma economia da segurança do sangue. Testes de sangue representam um mercado global próprio dominado por algumas poucas empresas multinacionais. Como será discutido, no caso dos testes NAT, a entrada neste mercado requer expertise em biologia molecular e nível adequado de automação (práticas, equipamentos), os quais representam barreiras importantes para os laboratórios de menor porte e ligados ao setor público.

$\mathrm{O}$ segmento de testes moleculares (NAT) para triagem de sangue representa a divisão mais ampla do mercado de testes diagnósticos moleculares, com uma taxa de crescimento anual de dois dígitos (CONSTANCE, 2010). ${ }^{2}$ Dois são os principais produtos NAT disponíveis no mercado global: o teste produzido em parceria pelas firmas Chiron Corporation e Gen-Probe, atualmente propriedade de outras duas empresas, Grifols e Horlogic, respectivamente; e o kit fabricado e comercializado pela Roche. A Grifols passou a integrar este mercado com a aquisição do segmento de testes de triagem de sangue da Novartis, em 2013, a qual, por sua vez, havia adquirido a Chiron, em 2006. A Horlogic começou a operar neste mercado em 2012, após sua fusão com a Gen-Probe. 
Em 2010, antes dessas mudanças de mercado, a parceria Chiron/Gen-Probe era a maior proprietária do segmento de testes de triagem de sangue, acompanhada pela Roche e Abbott, sendo que esta última comercializava imunoensaios e não teste NAT (CONSTANCE, 2010).

Antes da aquisição da unidade de diagnósticos da Novartis pela Grifols, em 2012, a comercialização do NAT era apontada como estratégica pela unidade de transfusão de sangue da Novartis, por representar mais da metade dos negócios dessa divisão. O segmento de imunoensaios, por outro lado, era considerado menos atraente por ter alto volume e baixo custo de mercado, comparativamente ao NAT. Este último, NAT, que exige uma manutenção relativamente alta, apoio no treinamento dos operadores/técnicos e instalação de máquinas, era um mercado em expansão, em especial na China, Indonésia e Índia (Q\&A, 2012).

Considerando-se o cenário de países que incorporaram o teste NAT na rotina da testagem de sangue, a grande maioria implementou os produtos Chiron/Gen-Probe e Roche. Em 2008, 22 países usavam testes Chiron/Gen-Probe e 18, os testes da Roche; em 7 desses países, ambos os testes eram usados. $\mathrm{Na}$ época, apenas quatro países (Alemanha, Áustria, Holanda e Escócia) produziam e usavam testes in house (não industrializados), ${ }^{3}$ mas um deles, a Holanda, já estava discutindo a aquisição de teste comercial (ROTH et al., 2012). A maioria dos países que tinham NAT estavam situados na Europa, o que reforça a expansão das fronteiras dessa tecnologia em direção aos mercados das economias emergentes.

\section{Objeto do estudo}

\section{O consórcio "NAT brasileiro" entre política de sangue e política industrial}

Em 5 de fevereiro de 2002, o Ministério da Saúde publicou o decreto MS/GM $\mathrm{n}^{\circ} 262$, exigindo que todos os bancos de sangue no Brasil adotassem o NAT para os vírus da Aids e da hepatite $\mathrm{C}$ na rotina de testagem de sangue, num prazo de seis meses. O mesmo ano (2002) foi marcado pelo final do segundo mandato de Fernando Henrique Cardoso (FHC) e a saída de seu ministro, José Serra, para concorrer à eleição presidencial. Serra tinha se tornado célebre em razão da resposta brasileira à epidemia de HIV, agregando tratamento e prevenção, com a produção local de antirretrovirais (ARVs) genéricos. A despeito do reconhecimento nacional e internacional de seu trabalho no MS, ele não foi eleito, sendo derrotado pelo 
candidato da oposição, Luiz Inácio Lula da Silva. Além disso, seu decreto não pôde ser imediatamente implementado, por questóes de disponibilidade e acessibilidade: os únicos dois produtos disponíveis no mercado internacional não estavam registrados no Brasil, e ainda que estivessem registrados, seu preço (em torno de 30 dólares por bolsa testada) era considerado, pelo governo brasileiro, muito elevado para importação e distribuição aos bancos de sangue vinculados ao sistema de saúde público (PETRY, 2013). A Portaria n 262 foi revogada pela Portaria MS/GM n ${ }^{\circ}$ 1.407 , de $1^{\circ}$ de agosto de 2002, postergando a inclusão do NAT pelos bancos de sangue do país por mais seis meses, período novamente ampliado para mais 12 meses, a partir da Portaria $n^{\circ} 79$, de 31 de janeiro de 2003. Finalmente, a Portaria $\mathrm{n}^{\circ} 112$, de 29 de janeiro de 2004, estabeleceu que a implantação do NAT deveria ocorrer em etapas e de forma gradativa, não definindo mais um prazo para a sua adoção por todos os serviços de hemoterapia.

Essa decisão do Ministério da Saúde se deu de forma associada a uma consulta ao laboratório de biotecnologia oficial do MS - o Instituto de Tecnologia em Imunobiológicos, Bio-Manguinhos, ligado à Fiocruz - para verificar se o país seria capaz de produzir uma versão local do NAT em escala industrial (projeto "NAT brasileiro"). Um consórcio tecnológico foi estabelecido por Bio-Manguinhos, com a inclusão de pesquisadores do Instituto de Biologia da Universidade Federal do Rio de Janeiro (UFRJ) e do Instituto de Biologia Molecular do Paraná (IBMP), os três a cargo do desenvolvimento tecnológico do kit. Também integraram a iniciativa a recém-criada Empresa Brasileira de Hemoderivados e Biotecnologia (Hemobrás), a qual apoiou financeiramente o projeto, e a Agência Nacional de Vigilância Sanitária (Anvisa), responsável pelo registro de produtos de saúde no Brasil. O IBMP e a UFRJ já estavam colaborando com Bio-Manguinhos no desenvolvimento de um teste de carga viral de HIV.

Tal iniciativa está, portanto, na interseção entre uma política pública de saúde na área do sangue e uma política industrial. A primeira enxerga a produção local do NAT como uma forma de incorporar um teste que aumentará a qualidade do sangue no Brasil. O consórcio também está conectado a uma política industrial no setor saúde que floresceu no país durante os anos 2000 e estimulou o desenvolvimento do complexo industrial da saúde a partir da produção, por laboratórios nacionais públicos e privados, das tecnologias usadas no SUS. Nesse contexto, uma planta industrial para produzir componentes de biologia molecular para o NAT foi inaugurada em agosto 
de 2009, após três anos de construção, em terreno do Instituto de Tecnologia do Paraná, onde fica o IBMP, ${ }^{4}$ a mesma instituição que, a partir dessa experiência, junto com Bio-Manguinhos, se engajou em outros projetos de P\&D de testes diagnósticos.

\section{Resultados e discussão}

\section{Negociar e reunir tecnologias: o desenvolvimento}

\section{e a produçáo do NAT brasileiro}

Iniciado em 2005, o consórcio NAT brasileiro incluiu o desenvolvimento tecnológico, a produção do kit, a implantação dos equipamentos nos bancos de sangue que realizam o teste, a formação de técnicos e a criação de um serviço de assistência técnica.

Nesta seção, propomos a "desmontagem" do kit NAT brasileiro, a fim de compreender as diferentes tecnologias que o compóem, assim como as possibilidades e os limites para o desenvolvimento e a fabricação do teste pelos atores participantes do consórcio. Como identificado, a presença de capacidades (planta industrial, recursos humanos, know-how para desenvolvimento e produção de insumos para testes moleculares e equipamentos necessários para a realização de testes) pode ser barreira mais importante para a produção local de testes diagnósticos in vitro que direitos de patentes, como ocorre no caso de cópia e produção de genéricos de medicamentos sintéticos (CASSIER; CORREA, 2003). Esta constatação se torna clara também em vista das diferentes estratégias adotadas pelo consórcio, como relatado em entrevistas, para adquirir cada um dos componentes tecnológicos que integram o kit NAT e a sua utilização na rotina de triagem de bolsas de sangue (entrevista 1).

Olhando o kit "desmontado", o teste NAT pode ser encarado como uma ferramenta tecnológica modular constituída por três tipos de componentes tecnológicos, como ilustra a Tabela 1: componentes de biologia molecular (o kit); elementos mecânicos e eletrônicos, representados pelos equipamentos utilizados para a realização das reaçôes do kit; e os softwares mobilizados para a organização dos dados relativos às bolsas de sangue testadas. Além desses três módulos, a realização do teste também inclui a utilização de consumíveis, como ponteiras, tubos e desinfetante. A decomposição do teste dá visibilidade à complexidade do kit, aos mercados que cada componente representa, assim como às diferentes decisões em termos de aquisição de componentes para o teste brasileiro (ONG; COLLIER, 2005). 
Tabela 1. Tecnologias componentes do NAT brasileiro

\begin{tabular}{|c|c|c|}
\hline \multicolumn{3}{|c|}{ Tecnologias componentes do NAT brasileiro } \\
\hline & Componentes & Origem das tecnologias $[\mathrm{N} / \mathrm{I}]^{*}$ \\
\hline $\begin{array}{l}\text { Componentes } \\
\text { mecânicos e } \\
\text { eletrônicos }\end{array}$ & $\begin{array}{l}\text { Equipamentos: } \\
\text { 1- Janus } \\
\text { 2- Biorobot MDX } \\
\text { 3- Termociclador ABI } 7500 \\
\text { Os equipamentos realizam o teste } \\
\text { em } 5 \text { etapas: } \\
\text { a) preparação dos pools de amostras } \\
\text { (Janus) } \\
\text { b) extração e purificação de ácidos } \\
\text { nucleicos (Biorobot MDX) } \\
\text { c) preparação e pipetagem da } \\
\text { reaçáo de amplificaçãa (Janus) } \\
\text { d) amplificação e detecção: } \\
\text { termociclador ABI } 7500 \\
\text { e) processamento de dados e } \\
\text { resultados (Janus) }\end{array}$ & $\begin{array}{l}\text { Perkin Elmer (I) } \\
\text { Qiagen (I) } \\
\text { Life Technologies (I) }\end{array}$ \\
\hline $\begin{array}{l}\text { Componentes } \\
\text { biotecnológicos }\end{array}$ & $\begin{array}{l}\text { Kit de biologia molecular: } \\
\text { 1- Módulo de extração (de ácidos } \\
\text { nucleicos) } \\
\text { 2- Módulo de calibração (vírus } \\
\text { calibrador) } \\
\text { 3- Módulo de amplificação (PCR) }\end{array}$ & $\begin{array}{l}1 \text { - Qiagen }(\mathrm{I}) \\
2 \text { - Bio-Manguinhos }(\mathrm{N}) \\
3 \text { - IBMP }(\mathrm{N} / \mathrm{I})\end{array}$ \\
\hline $\begin{array}{l}\text { Componentes } \\
\text { de TI }\end{array}$ & Softwares & $\begin{array}{l}\text { - Softwares dos equipamentos (I) } \\
\text { - Software de integraçáo e } \\
\text { rastreabilidade (I) } \\
\text { - Software de processamento dos } \\
\text { resultados (N) }\end{array}$ \\
\hline
\end{tabular}

Fonte: Entrevista 2 e Petry (2013). ${ }^{*}$ N: Nacional; I: Importado. 
Os componentes de biologia molecular do kit podem, ainda, ser decompostos em três blocos ou módulos, segundo uma organização criada pelos atores membros deste consórcio: um módulo de extração de ácidos nucleicos do sangue; um módulo de controle das reaçôes; e um módulo de amplificação dos ácidos nucleicos extraídos (entrevista 2).

O teste funciona como descrito a seguir: um pool (conjunto) de seis amostras é preparado, ao qual se acrescenta uma partícula calibradora (virus-like particle), que servirá como controle durante o ensaio (módulo de controle); em seguida, os ácidos nucleicos são extraídos (módulo de extração) e amplificados pela técnica de reação em cadeia da polimerase (PCR) em tempo real ${ }^{5}$ (módulo de amplificação). Cada submódulo é formado por itens de biologia molecular, como enzimas (Taq DNA polimerase e RT), sondas e tampão, que compóem o master mix, ${ }^{6}$ para a reação de amplificação; e a partícula calibradora para fazer o controle das reaçóes.

Além do teste, é importante visualizar toda a logística envolvida na testagem: coleta de sangue, transporte para o laboratório NAT e a realizaçáo do teste. Três equipamentos são utilizados para preparar o pool de amostras; fazer a extração dos ácidos nucleicos; para montar a reação de amplificação de ácidos nucleicos; e, finalmente, para amplificar os ácidos nucleicos e para a detecção da infecção. A divisão do teste em componentes (biotecnológicos, mecânicos e de tecnologia da informação - TI) e do kit em módulos (módulo de extração; módulo de calibração; módulo de amplificação) auxilia na compreensão das diferentes estratégias utilizadas pelo consórcio para adquirir cada um desses componentes.

No componente biotecnológico, cada módulo tem uma origem distinta: o módulo de extração de ácidos nucleicos é inteiramente importado da empresa multinacional alemã Qiagen; enquanto o módulo de amplificação - o cerne da técnica de PCR possui itens que resultam de transferência de know-how da mesma empresa (Qiagen) para o IBMP. O módulo de controle, composto principalmente pela partícula calibradora, foi um desenvolvimento dos virologistas da UFRJ em conjunto com pesquisadores de Bio-Manguinhos, sendo atualmente produzido por este último. Esse item, concebido para atuar como um controle individual de cada reação molecular, foi mencionado pelos entrevistados como o fator inovador do kit, alvo de um pedido de patente, ${ }^{7}$ servindo também para distingui-lo dos testes comerciais.

A história do desenvolvimento do vírus calibrador pelos pesquisadores da UFRJ é bastante peculiar. Esse componente foi originalmente concebido para outra 
iniciativa de teste in vitro a ser produzido por Bio-Manguinhos; nesse caso, um teste para determinação de carga viral de HIV. O teste a ser fabricado seria fruto de uma transferência de tecnologia por parte de uma empresa multinacional norteamericana. Finalmente, segundo os entrevistados, após um ano de negociaçôes e investimentos na produção do teste, a empresa proprietária do teste desistiu do acordo. ${ }^{8} \mathrm{Na}$ época, o Brasil não possuía uma planta industrial para a produção de itens de biologia molecular, impossibilitando o uso de licença compulsória de patentes relacionadas ao teste ou mesmo a engenharia reversa, em contraste com a experiência de Farmanguinhos e outros laboratórios farmacêuticos brasileiros com a cópia de ARVs (entrevista 3).

Ao contrário dos exemplos de conflitos entre empresas multinacionais e o Ministério da Saúde, com ameaça de utilização de flexibilidades patentárias como forma de se obter preços menores para ARVs, tanto sob a égide de José Serra, ainda no governo FHC, quanto, posteriormente, com Humberto Costa e José Temporão, já no governo Lula, a estratégia do consórcio NAT para desenvolver o kit se baseou principalmente na negociação com empresas internacionais para obtenção de tecnologias necessárias para o teste. Uma explicação plausível é o fato de Bio-Manguinhos ter uma vasta experiência com a produção de vacinas a partir de transferência de tecnologias advindas de empresas multinacionais. Embora o recurso ao uso de licença compulsória, como aventado no caso de ARVs, possa ter afetado a negociação da transferência do teste de carga viral, como especulado, a estratégia do consórcio, liderado por Bio-Manguinhos, continua a repousar na colaboração com os laboratórios internacionais.

Um dos entrevistados mencionou, assim, a contribuição da Qiagen e da Applied Biosystems (agora chamada de Life Technologies, parte da Thermo Fisher Scientific) ao consórcio, transferindo know-how para a produção de componentes de biologia molecular, como a que envolveu a transferência, pela Qiagen, de conhecimentos relativos à enzima DNA Taq polimerase. Da mesma forma, no desenvolvimento de tampóes para as reaçóes e o próprio master mix, na testagem do vírus calibrador e no uso da tecnologia de PCR em tempo real, os entrevistados nos falaram da colaboração. É claro que a participação dessas empresas esteve ligada a acordos comerciais relacionados à transferência de know-how, o que envolveu o pagamento de royalties para a parceira (Qiagen). Além disso, a empresa Qiagen é a mesma que fornece o módulo de extração, junto com o equipamento para a sua realização. 
Um dos entrevistados mencionou que, embora seja um item importante, outros fornecedores de produtos similares existem no mercado, não comprometendo, portanto, a "nacionalização" do teste NAT, pois o país estaria menos vulnerável à empresa caso esta desistisse de fornecer o módulo para o consórcio. Ademais, o número de extraçóes, considerado reduzido, uma vez que o teste é realizado em pools de seis amostras (e não individual), não justificaria o investimento na produção desse módulo (entrevista 2).

Assim, a nacionalização do NAT não significa que todos os componentes são produzidos localmente. Com efeito, a nacionalização é condicionada às decisôes estratégicas para negociar a aquisição das tecnologias, assim como dependente das prioridades e dos limites à fabricação local de todos os componentes do teste. $\mathrm{O}$ módulo de extração e os equipamentos são importados.

Os equipamentos para o teste são itens especialmente delicados no contexto da nacionalização de testes in vitro. $\mathrm{O}$ Brasil não possui a capacidade tecnológica para a fabricaçáo local desses equipamentos para a realizaçáo de testes moleculares (entrevista 4). Embora de alto preço, uma vez que a implementação dos testes foi centralizada em 14 bancos de sangue para a testagem de sangue em todo o país, ${ }^{9} \mathrm{o}$ número de equipamentos adquiridos (28 equipamentos) não justificaria investimentos na produção local de tais equipamentos apenas para o projeto NAT (entrevista 2).

Finalmente, outro componente importante - um dos softwares, aquele para leitura dos resultados - foi desenvolvidos por Bio-Manguinhos. É também o laboratório público que reúne os três módulos e fornece o kit (produto final) aos laboratórios que testam as bolsas de sangue com a tecnologia NAT, além de realizar a gestão de serviços para realização do teste. Na verdade, este último seria um quarto componente do kit, o qual envolve treinamento de profissionais, além de assistência técnica (no caso dos equipamentos, feito por cada fabricante, mas gerida por BioManguinhos) e científica (entrevista 2).

O NAT brasileiro para uso em HIV e HCV foi registrado na Anvisa em 27 de dezembro de 2010; um novo registro foi obtido em 3 de novembro de 2014, para a inclusão do HBV. O teste do consórcio foi progressivamente implantado nos 14 sítios testadores, que passaram a formar uma rede centralizada de testagem de sangue com NAT. Apenas em 2012, quando o NAT brasileiro já tinha sido localizado e industrializado, que um novo decreto sobre o NAT foi publicado, neste caso, para consultar a sociedade civil sobre a recomendação da Comissão Nacional 
de Incorporação de Tecnologias no SUS (CONITEC) para incluir o teste. No ano seguinte, um decreto estabeleceu como obrigatória a utilização de triagem de bolsas de sangue com NAT em todos os bancos de sangue.

\section{Uma tecnologia brasileira?}

As estratégias acima descritas, adotadas pelo consórcio para adquirir as tecnologias e know-how relacionados aos diferentes componentes que juntos constituem o teste final, não podem ser deslocadas do contexto externo do mercado global de testes in vitro.

Kleinman (1998), ao refletir sobre um laboratório universitário que trabalhava na interface entre pesquisa básica e pesquisa aplicada, nos Estados Unidos, apontou as influências de estruturas já construídas na conformação das práticas de pesquisa em laboratório. Um aspecto mencionado pelo autor diz respeito à influência da lei de propriedade intelectual (PI) nas atividades de laboratórios universitários: o autor (op. cit.) traz como exemplo desse aspecto a ideia de produzir uma versão in house (não industrializada) de uma enzima usada em um projeto de pesquisa. Ainda que sustentada por uma boa razão (o produto existente no mercado não era compatível com as necessidades do laboratório) e prevista na própria legislação norte-americana (cláusula de "uso experimental" de um objeto patenteado), essa "solução" foi logo descartada pelos pesquisadores de um laboratório universitário, a fim de evitar que este viesse a ser listado como um "violador de direitos patentários" pela empresa proprietária das patentes da enzima nos Estados Unidos.

Da mesma forma, Bio-Manguinhos e o IBMP, ao decidirem atuar em um mercado monopolizado por algumas grandes companhias detentoras de patentes e conhecimentos envolvendo componentes passíveis de interesse ou eventualmente necessários ao kit brasileiro, buscaram antes estabelecer acordos comerciais de colaboração com o setor privado. Este foi o caso da obtenção de know-how sobre a enzima DNA Taq polimerase usada no kit NAT brasileiro; tendo este uso envolvido o pagamento de royalties para a outra parte, a empresa Qiagen. A fim de obter tecnologias e know-how que poderiam ulteriormente vir a ser aplicados a outros projetos de $\mathrm{P} \& \mathrm{D}$, foram dados, em troca, mercados à empresa (no caso, a Qiagen), que passa a fornecer ao consórcio o equipamento e os insumos para a realização da etapa de extração de ácidos nucleicos. 
Concomitantemente, o consórcio NAT se insere também na cultura de patenteamento de tecnologias, uma tendência crescente no âmbito das instituiçôes de pesquisa brasileiras. Assim, as instituiçôes do consórcio brasileiro integram esse sistema ao aceitarem a crença geral da eficácia dos direitos de PI como promotores de inovação, que podem atrair interesse comercial para o seu trabalho (KLEINMAN, 1998). Outra justificativa para a busca de patentes é o possível uso defensivo do mesmo contra a apropriação de tecnologias por multinacionais.

A despeito do forte apoio da Coordenação do Sangue e de Hemoderivados do Ministério da Saúde à iniciativa, garantindo o mercado público - ou seja, a compra e fornecimento de kits para triagem das bolsas de sangue dos bancos que atendem o SUS -, a política de nacionalização de produtos sanitários não foi unanimemente aceita nem totalmente compreendida dentro do próprio governo. A iniciativa do NAT brasileiro é, de fato, complexa, por envolver uma variedade de componentes e diferentes estratégias para adquirir cada uma das tecnologias que o compóem.

A leitura do consórcio acaba se polarizando em dois discursos: um oficial, que enaltece a produção de "tecnologias nacionais"; e outro cético, questionador da capacidade de instituiçôes locais de produzir e inventar tecnologias de alta capacidade. ${ }^{10}$ Esse caso parece ressonar as reflexôes de Pollock (2014) sobre o papel implicitamente atribuído aos países do Norte enquanto os principais lugares para produção de conhecimento e de inovaçôes biomédicas, que serão utilizadas nos países do Sul.

\section{Contribuiçóes do consórcio NAT para o sistema de inovação em saúde}

Esta iniciativa também tem uma implicação para a criação de capacidades locais para o sistema de inovação em saúde, em termos de infraestrutura e recursos humanos. Ela tem permitido a emergência de novos atores no campo da produção de testes in vitro no Brasil, com a participação do IBMP e de Bio-Manguinhos na produção de itens de biologia molecular e a inclusão de universidades na invenção de testes para diagnóstico.

É possível verificar o estabelecimento de uma rede de laboratórios públicos, universidades e institutos de pesquisa brasileiros colaborando para produzir e inventar itens para compor testes in vitro. Um programa criado pelo antigo Ministério da Ciência, Tecnologia e Inovação, em 2008, chamado "Institutos Nacionais de Ciência e Tecnologia”, ajudou a formalizar uma rede que já estava em construção. Essa rede 
desenvolveu, por exemplo, um multiteste baseado na tecnologia de microarranjos líquidos (liquid microarrays) para substituir os testes sorológicos realizados em separados nos bancos de sangue por um único teste (multiplex). Se, por um lado, o multiteste se baseia na tecnologia e no equipamento desenvolvido e patenteado por uma empresa norte-americana; por outro, utilizam-se microesferas de poliestireno desenvolvidas pelos físicos da Universidade Federal do Paraná (UFPR), um insumo fundamental para a realização do teste multiplex a partir dessa metodologia. (entrevistas 5 e 6). Visualiza-se aqui a reverberação da racionalidade do projeto NAT: incorporar uma nova tecnologia pode obrigatoriamente envolver a importação de alguns itens. Porém, se a dependência tecnológica de certos itens se apresenta como contínua, ela é relativa, uma vez que a ela se associa o desenvolvimento local de outros componentes.

Outro exemplo de aproveitamento de capacidades tecnológicas e de infraestrutura criadas localmente pelo consórcio foi o desenvolvimento, em colaboração, de um teste NAT para diagnóstico de zika, dengue e chikungunya por Bio-Manguinhos e pelo IBMP, anunciado em janeiro de 2016 pelo MS e registrado em 2017. Assim, fica claro que as capacidades criadas durante os trabalhos de pesquisa e desenvolvimento do consórcio NAT são usadas em novos projetos, reforçando um ciclo virtuoso de aprendizado tecnológico, que pavimenta a formação de um sistema de inovação no campo dos IVDs no Brasil, com forte apoio do Estado e orientado para atender às necessidades de saúde pública locais.

\section{Conclusão}

A análise do consórcio NAT contribui para a reflexão sobre as razóes para o encorajamento governamental à fabricação local de tecnologias de saúde por instituiçóes nacionais públicas e privadas. Atores envolvidos na iniciativa "NAT brasileiro" a qualificam como "nacionalização", uma palavra polissêmica que tem como um dos seus significados "trazer para a propriedade e controle do governo recursos e atividades anteriormente operadas por negócios privados e organizaçôes locais" (BLACK et al., 2009). Este significado parece apropriado ao caso analisado, uma vez que o consórcio era uma iniciativa do Estado brasileiro e o produto final teve seu uso restrito ao sistema de saúde público. Mas além das razóes econômicas seguindo o argumento central da substituição de importação, há outras de saúde 
pública para a nacionalização, já que a tecnologia pode ser usada para responder a necessidades sanitárias do país. Finalmente, há razóes de autonomia para a nacionalização tecnológica, na medida em que esta afirma a capacidade nacional de oferecer uma tecnologia de interesse da população brasileira.

Ao mesmo tempo, a nacionalização tecnológica envolveu uma série de negociaçôes para adquirir conhecimento e tecnologias, além da classificação e da identificação das tecnologias com vistas à escolha das que viriam a ser alvo da fabricação local e aquisição de conhecimento. Algumas dependências tecnológicas foram superadas, enquanto outras, mantidas. A nacionalização também envolveu a reunião de tecnologias diferentes e o fornecimento do produto final com todos os serviços relacionados (mesmo se nesses casos o laboratório nacional Bio-Manguinhos ainda continue como intermediário). O processo de localização tecnológica - traduzido por seus atores como nacionalização do teste - foi, portanto, altamente influenciado por configuraçôes globais e dependente de negociaçôes com empresas multinacionais. ${ }^{11}$

\section{Agradecimentos}

Os autores agradecem às pessoas e instituiçôes que aceitaram participar desta pesquisa; à Agência Nacional Francesa de Pesquisa sobre Aids e Hepatites Virais (ANRS) e à Coordenação de Aperfeiçoamento de Pessoal de Nível Superior (CAPES), pelo financiamento do projeto (ANRS Número 12307 - B74). Os autores também agradecem às seguintes pessoas, que leram este artigo e contribuíram para sua revisão: Andy McDowell, Mathieu Quet, Ashveen Peerbaye, Jessica Pourraz, Ilana Lowy, Nils Graber, Alila Brossard e Juliana Veras.

\section{Referências}

BLACK, J.; HASHIMZADE, N.; MYLES, G. D. A dictionary of economics. Oxford: Oxford University Press, 2009.

BUSBY, H.; KENT, J.; FARRELL, A.-M. Revaluing donor and recipient bodies in the globalised blood economy: Transitions in public policy on blood safety in the United Kingdom Introduction: perspectives on blood and tissue economies. Health, v. 18, n. 181, p. 79-94, 2014. Disponível em: <https://doi.org/10.1177/1363459313476966>.

BUSCH, M. P.; DODD, R. Y. Nucleic Acid amplification testing and blood safety: what is the paradigm? Transfusion, v. 40, p. 1157-60, 2000. 
CASSIER, M.; CORREA, M. Patents, innovation and public health: Brazilian public-sector laboratories' experience in copying AIDS drugs. In: ANRS. Economics of Aids Aid and access in developing countries. Paris: ANRS, 2003. p. 89-107. Disponível em: <http://193.144.75.244/ epip/documentos/Cassier\%27s paper.pdf>.

CHANDRASHEKAR, S. Half a decade of mini-pool nucleic acid testing: Cost-effective way for improving blood safety in India. Asian J Transfus Sci, v. 8, p. 35-38, 2014.

CHAVES, G. C.; VIEIRA, M. F.; REIS, R. Acesso a medicamentos e propriedade intelectual no Brasil: reflexóes e estratégias da sociedade civil. SUR - Revista Internacional de Direitos Humanos, p. 170-198, 2008. Disponível em: <http://www.surjournal.org/conteudos/getArtigo8. php?artigo=8,port,artigo_chaves.htm $>$.

CONSTANCE, J. A. The future of molecular diagnostics: innovative technologies driving market opportunities in personalized medicine. 2010.

ENGEL, N. New diagnostics for multi-drug resistant tuberculosis in India: Innovating control and controlling innovation. BioSocieties, v. 7, n. 1, p. 50-71, 2012.

FLANAGAN, P.; SNAPE, T. Nucleic acid technology (NAT) testing and the transfusion service: a rationale for the implementation of minipool testing. Transfusion Medicine. Oxford, v. 8, n. 1, p. 9-13, 1998.

GENOMEWEB. New Novartis Dx president discusses nucleic acid testing, blood screening business. 2012. Disponível em: <https:/www.genomeweb.com/pcrsample-prep/qa-new-novartis-dxpresident-discusses-nucleic-acid-testing-blood-screening-busi>.

GOMPERTS, E. D. Gammagard ${ }^{\oplus}$ and reported hepatitis $\mathrm{C}$ virus episodes. Clinical Therapeutics, v. 18-B, 1996.

HANS, R.; MARWAHA, N. Nucleic acid testing-benefits and constraints. Asian Journal of Transfusion Science, v. 8, n. 1, p. 2-3, 2014. Disponível em: <https://www.ncbi.nlm.nih.gov/ pmc/articles/PMC3943139/>.

HOURFAR, M. K. et al. Experience of German Red Cross blood donor services with nucleic acid testing: Results of screening more than 30 million blood donations for human immunodeficiency virus-1, hepatitis $\mathrm{C}$ virus, and hepatitis B virus. Transfusion, v. 48, n. 8, p. $1.558-1.566,2008$.

JERSILD, C.; HAFNER, V. Blood transfusion services. International Encyclopedia of Public Health. New York: Academic Press, 2008.

KLEINMAN, D. L. Untangling context : understanding in the a University World Commercial. Science, Technology, \& Human Values, v. 23, n. 3, p. 285-314, 1998. 
KRIEGER, M. et al. Cooperação técnico-científica entre instituiçôes públicas e privadas para incorporação tecnológica: impacto da nacionalização do teste NAT HIV e HCV na ampliação do acesso e na formação de base tecnológica no âmbito do Sistema Único de Saúde. Revista Divulgação em Saúde para Debate, v. 50, 2013. Disponível em: <files/2746/DSD50_ Hemobras_Web1.pdf>.

LATOUR, B. Ciência em ação. 2. ed. São Paulo: Unesp, 2011. Disponível em: <http:// editoraunesp.com.br/catalogo/9788539301904,ciencia-em-acao-2-edicao>.

WORLD HEALTH ORGANIZATION. Screening donated Blood for transfusion - transmissible infections: recommendations. Geneva: WHO, 2009.

WORLD HEALTH ORGANIZATION. Global Database on Blood Safety, Summary Report 2011. Geneva: WHO, 2011.

WORLD HEALTH ORGANIZATION. 19th WHO Model List of Essential Medicines. Geneva: WHO, 2015. Disponível em: <http://Www.Who.Int/Medicines/Publications/ Essentialmedicines/En>.

ONG, A.; COLLIER, S. J. Global assemblages: technology, politics, and ethics as anthropological problems. Blackwell Publishing, 2005.

PETRY, A. Implantação dos Testes de Amplificação de Ácidos Nucléicos HIV/HCVBio-Manguinhos na triagem de doadores de sangue: questóes epidemiológicas e logísticas. 2013. Tese (Doutorado em Saúde Coletiva) - Universidade Federal de Santa Catarina, Florianópolis, 2013.

POLLOCK, A. Places of pharmaceutical knowledge-making: global health, postcolonial science and hope in South African drug discovery. Social Studies of Science, v. 44, n. 6, p. 848 873, 2014.

ROTH, W. K. et al. International survey on NAT testing of blood donations: expanding implementation and yield from 1999 to 2009: International Forum. Vox Sanguinis, v. 102, n. 1, p. 82-90, 2012.

SANTOS, L. A. de C.; MORAES, C.; COELHO, V. S. P. Os anos 80: a politização do sangue. Physis: Revista de Saúde Coletiva, v. 2, n. 1, p. 107-149, 1992.

WENDEL, S. et al. NAT application in Brazil: some additional aspects to be considered. Revista Brasileira de Hematologia E Hemoterapia, v. 31, n. 2, p. 112-113, 2009. Disponível em: <http:// www.scielo.br/scielo.php?pid=S1516-84842009000200014\&script=sci_arttext\&tlng=en>.

WENDEL, S. et al. Primary screening of blood donors by nat testing for HCV-RNA: development of an "in-house" method and results. Revista do Instituto de Medicina Tropical de São Paulo, v. 49, n. 3, p. 177-185, 2007. Disponível em: <http://www.scielo.br/scielo. php?pid=S0036-46652007000300008\&script=sci_arttext $>$. 


\section{Lista de entrevistas (por ordem de aparecimento no texto)}

- Entrevista 1, Vice-diretor de desenvolvimento tecnológico do IBMP, Curitiba, 4/9/2014;

- Entrevista 2, Gerente do programa de desenvolvimento de reativos para testes diagnósticos, Bio-Manguinhos, Rio de Janeiro, 7/2016;

- Entrevista 3, Vice-diretor de desenvolvimento institucional do IBMP, Curitiba, 26/7/2015;

- Entrevista 4, Diretor do Instituto de Biologia da UFRJ, Rio de Janeiro, 25/8/2015;

- Entrevista 5, Diretor do ICC/Fiocruz-Paraná, Curitiba, 4/9/2014;

- Entrevista 6, Professor do Departamento de Física da UFPR, Curitiba, 4/9/2014.

\section{Notas}

${ }^{1}$ De acordo com as estimativas da Organização Mundial da Saúde, pelo menos 39 países não realizam testes laboratoriais no sangue doado, e $47 \%$ das doaçôes em países de baixa renda são testadas em laboratórios sem controle de qualidade (WHO, 2011).

${ }^{2}$ Este segmento representa $24 \%$ do mercado global de testes moleculares, com uma taxa anual de $15 \%$ de crescimento (CONSTANCE, 2010).

${ }^{3}$ No Brasil, um hospital privado de São Paulo (Sírio-Libanês) reportou realizar teste NAT para HCV e HIV desde 1998, utilizando uma tecnologia in house desenvolvida para a instituição. Outros dois hospitais privados de São Paulo também utilizaram teste in house em sua rotina de testagem de sangue (ROTH et al., 2012; WENDEL et al., 2007; WENDEL et al., 2009). O uso do teste não industrializado nessas instituições foi, posteriormente, substituído por testes comerciais em 2007.

${ }^{4}$ Em paralelo à inauguração da planta industrial do IBMP, a qual o tornou uma instituição de desenvolvimento tecnológico e produção industrial, a Fiocruz estabeleceu uma unidade técnico-científica no antigo prédio do IBMP, o Instituto Carlos Chagas (ICC).

${ }^{5}$ A técnica é chamada de PCR em tempo real, uma vez que o progresso do PCR é monitorado enquanto está acontecendo através da leitura da intensidade da fluorescência por ciclo (PETRY, 2013).

${ }^{6} \mathrm{O}$ master mix de PCR é uma solução pré-misturada e pronta para uso, composta por enzimas, primers, sondas e tampão de reação em concentraçôes ótimas, e outros componentes necessários para a amplificação de ácidos nucleicos por PCR.

${ }^{7} \mathrm{O}$ documento de patente inclui tanto a detecção do HIV, quanto a quantificaçáo de carga viral, cobrindo, portanto, o diagnóstico e o monitoramento de HIV. O pedido, depositado no INPI em 16 de março de 2006 pela Fiocruz (PI0600715-5A2), incluiu pesquisadores e inventores de Bio-Manguinhos e da UFRJ. A patente foi concedida no Brasil em 3 de outubro de 2017.

${ }^{8}$ Especula-se que a empresa multinacional norte-americana detentora da tecnologia tenha desistido da transferência de tecnologia em razão de seu vínculo comercial com a Abbott, que estava interessada no mercado brasileiro de testes de monitoramento de HIV. Também se mencionou a existência de litígio entre a companhia e o governo brasileiro em razão de um medicamento patenteado pela Abbott, 
o Kaletra (lopinavir + ritonavir). A dificuldade de negociaçáo para reduçáo de preço do medicamento levou o governo brasileiro a indicar a sua intenção de usar pela primeira vez uma licença compulsória para uma patente farmacêutica, chegando a declarar o medicamento como sendo de interesse público, um primeiro passo para a utilização da flexibilidade patentária. Esta, no entanto, acabou não ocorrendo para o Kaletra, após assinatura de contrato entre o governo e a empresa, restringindo o uso de licença compulsória para o ARV (CHAVES et al., 2008).

${ }^{9}$ Com o objetivo de economizar recursos e evitar desperdício dos kits (cada kit comporta a detecção de até 552 amostras), decidiu-se pela centralização do serviço de testagem por NAT em 14 sítios testadores, que foram escolhidos entre os hemocentros estrategicamente definidos nas cidades e capitais. Os sítios testadores são os hemocentros de Florianópolis, Brasília, Recife, Rio de Janeiro, São Paulo, Belo Horizonte, Manaus, Belém, Campinas, Ribeirão Preto, Curitiba, Cuiabá e Salvador (PETRY, 2013).

${ }^{10}$ Confrontamo-nos com essa divergência de posiçôes durante uma visita a dois diferentes departamentos do Ministério da Saúde, em 2015.

${ }^{11} \mathrm{~K}$. Kameda realizou as entrevistas, a análise dos dados e redação da versão final, respondendo por seu conteúdo. M.C.V. Corrêa e M. Cassier orientaram a metodologia, foram responsáveis pela revisão teórica do artigo e pela redação final e respondem por seu conteúdo. 


\section{Abstract}

The introduction of nucleic acid tests (NAT)

for blood screening in the Brazilian public

healthcare system: technological arrangements

for the nationalization of the "Brazilian NAT"

Nucleic acid based amplification tests (NAT)

are employed as complementary tools to control

the transmission of infectious diseases through

contaminated blood. In 2002, a decree from the

Brazilian Ministry of Health made compulsory the

use of NAT by all the blood services in the country, a

measure that was challenged by costs related to the test incorporation. As the strategy to introduce the test in the blood banks serving the public healthcare system (Sistema Único de Saúde), a public Consortium was constituted to develop a local version of the kit. On the basis of qualitative fieldwork, the authors investigate the strategies used by the Brazilian laboratories and universities to nationalize the kit through capturing and assembling its various components. The paper contributes to revealing the challenges and limits to the production of in vitro tests for infectious diseases in Brazil, as well as the repercussion of such an initiative to the national healthcare innovation system.

> Keywords: blood safety; diagnostic tests; nucleic acid based tests (NAT); HIVIAids; viral hepatitis; Unified Healthcare System (SUS). 